\title{
An investigation of high lithium concentrations
}

\author{
D. H. Myers and M. J. Hallworth
}

Tho circumstances aseocleted with high thilum concentrations detected by 23 distilet laboratories in the Weat Midiends during a 22 month period were inventigated.

The effects of drugs are studied in the laboratory, in clincial trials and in day to day use. The latter has come to be regarded as clinical audit.

Many publications attest to the beneficial and toxic effects of lithium, and to the narrow dose range between the two ${ }^{1}$. Although serum lithium concentration is the best monitor of lithium toxicity, it is only an indirect measure; in particular, in unsteady state conditions it will not be an accurate index of tissue toxicity, and high lithium levels may precede (Sellers et al, 1982) or follow (Amdisen, 1980) intoxication. Furthermore, patients as well as their individual organs vary in susceptibility to the toxic effects of lithium.

There is therefore no threshold serum concentration at which lithium can be said to be toxic. Nevertheless, it is convenient to regard concentrations of $1.5 \mathrm{mmol} / 1$ or more as being in the toxic range, since such concentrations are potentially fatal.

This investigation examined the circumstances associated with lithium values in the toxic range in the West Midlands Reglon during a 22 month period.

\section{The atudy}

The 23 participating laboratories sent a short questionnaire to any doctor who had requested a lithium estimate proving to have a value of $1.5 \mathrm{mmol} / 1$ or more. The investigation spanned the period from January 1991 to October 1992. Where more than one estimate in the toxic range arose from the same episode of toxicity, the maximum value was taken as the index value.

1. Technically, a low therapeutic ratio, that is, the ratio of the median lethal dose to the median effective dose.

\section{Findings}

Fifty-two separate instances of toxic values were recorded in 48 patients, one patient experiencing four and another patient two separate episodes (Table 1). The patient with four separate episodes was deliberately maintained at lithium values of about $1.2 \mathrm{mmol} / \mathrm{l}$, because only then, the respondent reported, was there freedom from disabling and frequent relapse.

The mean age of the patients who attained toxic levels was 58 years (s.d. $=16$ years, range 18 to 84 years). Thirty-six were female, 12 male. In 47 instances the patient was established on lithium. in four treatment was being initiated, and in one treatment had ended, the overdose coming from the remaining supply. The mean of the toxdc values was $2.0 \mathrm{mmol} / 1$ (s.d. $=0.80$, range $1.5-5$ ). The mean period elapsing between the toxic episodes and a previous lithium estimate was 6.7 weeks with an interquartile range of $2-8.8$ weeks.

\section{Table 1. Stated reason for high lithlum values}

\begin{tabular}{ll}
\hline Blood sampled too soon after last dose & $9(3)^{\circ}$ \\
Deliberate overdose & 5 \\
Accidental overdose (patient had confusional & 1 \\
state) & 12 \\
Dose too high & $2(1)$ \\
Urinary infection & 1 \\
Other renal disorder & $6(2)$ \\
Concurrent diuretic & $9(8)$ \\
Dehydration (depression contributing in 2 & \\
instances) & 1 \\
Treatment plan (to keep at 1.2 mmol/l) & $3(2)$ \\
'Chest infection' & $1(1)$ \\
Congestive cardlac fallure & 2 \\
Poor compllance & 1 \\
Formulation changed & 1 \\
Clinical deterioration & 2 \\
Hot weather & 5 \\
Unknown &
\end{tabular}

"In several patients, more than one reason for an episode of intoxication was given. The value in parentheses glves the number of lnstances of the quoted reason being associated with another couse. Thus, of the 9 instances of blood being sampled too soon after the last dose, three were associated with some other couse. 
Of the 30 respondents who told patients how long they should wait after their last dose before venesection for estimation, 20 quoted Amdisen's (1987) recommendation of 12 hours and seven others periods ranging from seven to 15 hours. Three quoted not a fixed period but a range so wide as to vitiate the estimate.

\section{Some instances of intoxication}

One patient who took a deliberate overdose had a maximum lithium value of $9.5 \mathrm{mmol} / 1$ and died, despite a reduction to $2.5 \mathrm{mmol} / 1$ on dialysis, probably because of the slow clearance of lithium. A 67-year-old woman on lithium was admitted to a general hospital with dehydration and a urinary infection. Her blood urea was $36.4 \mathrm{mmol} / 1$ (normal 2.3-8). Lithium was prescribed but she refused it - refusing medication in hospital can sometimes be good for your health.

\section{Comment}

How might lithium intoxication be avoided? Educating both patient and doctor is crucially important. Peet \& Harvey (1981) advocate the use of videotapes to educate patients. As with electroconvulsive therapy, there is a strong case for devoting a special session to lithium in postgraduate psychiatric training. Letters to family doctors when treatment is initlated might contain a concise statement of the monitoring recommendations and a reminder of adverse interactions and of the dangers of lithium during pregnancy.

The most difficult decision falls to the family doctor - whether, during intercurrent illness, to continue lithium, possibly at a reduced dose, or to stop it. The risk of affective relapse has to be weighed against that of lithium intoxication. Mander \& Loudon (1988) reported that $50 \%$ of a group of patients with a history of mania relapsed within two weeks of lithium being deliberately stopped. Margo \& McMahon (1982) reported rapid relapse of four patients taken off lithium in a drugs trial and Cordess (1982) gives a brief but useful review of other instances. Even reducing the dose of lithium may precipitate relapse (Tyrer et al, 1983). Suppes et al (1991) published a risk of relapse curve of patients taken off lithium but without confidence intervals for the very early relapse risk, possibly because there were too few instances to provide acceptably narrow limits. It is not known how many patients have suffered morbidity or died from lithium toxicity during intercurrent illness.

In practice the problems likely to be encountered are:

(a) Diarrhoea and vomiting. Either may be manifestations of toxicity. Both can result in marked loss of fluid and electrolytes, vomiting interferes with lithium absorption, and mild diarrhoea may itself be caused by lithium even at therapeutic doses. These complex circumstances collectively constitute a good case for stopping lithium temporarily.

(b) Relapse of affective disorder with significantly reduced food and fluid intake. Relapse of this severity requires in-patient care.

(c) Fever. Unless there are domiclliary facllitles for frequent monitoring and for ensuring adequate fluid intake, lithium is better stopped or the patient admitted.

(d) Urinary infection. Since it is not always possible at onset for a family doctor to know whether the infection extends beyond the bladder (Davison \& Lambie, 1991), It is safer to assume that it does and to stop lithium temporarily.

On these considerations, the general practitioner might reasonably resolve to stop lithium during any but the most trivial intercurrent illness, until a lithium estimate has been done, and to expect a psychiatrist to contribute to further management.

\section{Acknowledgements}

We are most grateful to the staff of the participating laboratories, to colleagues who answered the questionnaire, and to Mrs Margaret Nicholls.

\section{References}

AMDisen, A. (1980) Monttoring ththtum dose levels: clinical aspects of serum lithium estimation. In Handbook of Lithium Therapy (ed. F. Nell Johnson), pp. 179-195. Lancaster: MTP Press.

- (1987) The 12-hour standardized serum lithtum. In Depression and Mania: Modern Ltthium Therapy (ed. F. Nell Johnson) pp. 88-91. Oxford: IRL Press.

CorDEss, C. (1982) 'Rebound' manta after lithtum withdrawal? Brttish Journal of Psychiatry, 141, 431.

DAVISON, A. M. \& LAMBIE, A. T. (1991) Diseases of the kddney and gentto-urinary system. In Davidson's Prtnctples and Practice of Medictne (16th ed) (eds C. R. W. Edwards \& I. A. D. Bouchier), pp. 547-606. Edinburgh: Churchill Ltvingstone.

MANDER, A. J. \& LOUDON, J. B. (1988) Rapid recurrence of mania following abrupt discontinuation of lithium. Lancet, th, 15-17.

MARGO, A. \& MCMAHON, P. (1982) Lithium withdrawal triggers peychosis. Brttsh Joumal of Psychiatry. 141. 407.

PEET, M. \& HARVEY, N. S. (1991) Lthtum maintenance: a standard education programme for patients. Brttish Journal of Psychiatry, 168, 197-200.

SELLER, J., TYRER, P., WhItELEY, A., et al (1982) Neurotoxdc effects of Hthium with delayed rise in serum lthium levels. Brttish Joumal of Psychiatry, 140, 623-625. 
Suppes, T., BnLdessnean, R. J., Faedon, G. L., et al (1991) Piak of recurrence following discontinuation of ththtum treatment in btpolar disorder. Archtues of General Psychiatry, 48, 1082-1088.

TYreser, S. P., Shopsan, B. \& Aronson, M. (1983) Dangers of reducing lithium. Brttsh Joumal of Psychtatry. 148. 427.
D. H. Myers, Consultant Psychifatrist, Shelton Hospital Shrewsbury SY3 8DN; and M. J. Hallworth, Consultant Blochemist, Royal Shrewsbury Hospital, Shrewsbury SY3 8DN

-Correspondence

\title{
An investigation into lithium monitoring
}

\author{
D. H. Myers and M. J. Hallworth
}

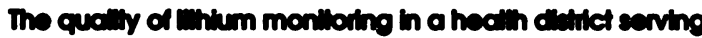
a popilation of 460000 wos studied over a patod of a yeer. The following indiences of poor montioing were

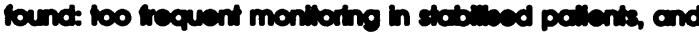
tollurs to take action when mhium vatues tell below $0.3 \mathrm{mmol} / \mathrm{h}$ or roes cbove $1.0 \mathrm{mmol}$. Woys of improving the stenderd of moniloing are condedered.

Precautionary measures can be overdone. The British National Formulary (BNF, British Medical Association \& Royal Pharmaceutical Society of Great Britain. 1995) used to advocate routine monthly monitoring of serum lithium. Schou (1988) suggested that routine monitoring is not worth the cost or effort, a refreshing statement on a topic that needed simplification. The issue turns on whether patients, once stabilised, will remain so. Kehoe \& Mander (1992) found that in 18 of 458 patients there was a gradual increase in serum lithium concentration during the course of a year, sufficient to require dose reduction. Such patients were found to have an unexplained $18 \%$ lower creatinine clearance rate than controls (Kehoe, 1994). This is important because 95\% of ingested lithium is excreted renally (Dyson et al, 1987). Until more is known, it is reasonable to follow the current BNF (1995) recommendation of monitoring at 3-monthly intervals or even 6monthly in young and middle-aged patients who are reliable (Ferrier et al, 1995).

However, there is no disagreement that it is essential to estimate serum lithium at the start of treatment, during intercurrent lliness, and if there is the slightest suspicion of intoxication.

\section{The study}

The Biochemistry Laboratory of the Shropshire District Health Authority, one of the 23 district laboratories in the West Midlands Region, keeps a record of all lithium estimates, together with information culled from the request forms. The quality of monitoring was assessed from these data which covered the interval from 1st January 1991 to 31st October 1992. All estimates were included in the study.

The time elapsing between two consecuttve estimates is referred to as the 'interval' of the second estimate.

The estimates were considered as four classes, the boundaries being dertved from the BNF(1995):

(a) 0-0.3 mmol/1: probably too low to be effective;

(b) 0.4-1.0 mmol/l: the recommended therapeutic range;

(c) 1.1-1.4 mmol/1: effecttve but high, and usually incurring unnecessarly severe side-effects; and

(d) 1.5 and above, 'toxic'.

If any lithium value lay outside the BNF range $(0.4-1.0 \mathrm{mmol} / \mathrm{l})$, or if any interval was stx months or more, or less than one month, further information was sought from case notes and from family doctor records.

\section{Findings}

\section{General}

The mean value of the 2697 lithium estimates was $0.63 \mathrm{mmol} / 1 ; 213$ (7.9\%) fell below the BNF range, 64 (2.4\%) fell in the range 1.1-1.4 mmol/1. and $14(0.5 \%)$ were in the toxic range. 